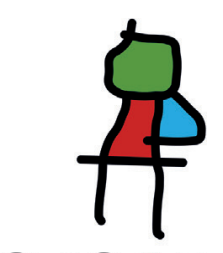

SEICAP

\section{Allergologia et \\ immunopathologia}

Sociedad Española de Inmunología Clínica, Alergología y Asma Pediátrica

\title{
Real-World Safety and Effectiveness Evidence of a Microcrystalline Tyrosine-Associated Mite Allergoid in Children and Adolescents with Allergic Rhinitis
}

\author{
Anna Sala-Cunilla*, Zulay M. Almeida-Sánchez ${ }^{\mathrm{b}}$, Ignacio García-Núñez ${ }^{\mathrm{c}, \mathrm{d}}$, Sofia Laíne, \\ Juan A. Martínez-Tadeof, Maria D. Martoss ${ }^{\mathrm{g}}$, Ramón Núñez ${ }^{\mathrm{h}}$, Mercedes Ramírezí, \\ Anna Boronat ${ }^{j}$, Carla Torán-Baronaj, José L. Justiciaj
}

${ }^{a}$ Allergy Section, Internal Medicine Department, Hospital Universitari Vall d'Hebrón, Barcelona, Spain

${ }^{b}$ La Palma General Hospital, La Palma, Spain

'Pneumokal Research Institute, S.L. Estepona, Málaga, Spain

${ }^{d}$ Allergology and Pneumology Department, Hospital Quirónsalud Campo de Gibraltar, Los Barrios, Cádiz, Spain; ${ }^{e}$ Hospital General de Catalunya, Sant Cugat del Vallès, Barcelona, Spain

fUniversity Hospital Nuestra Señora de la Candelaria, Santa Cruz de Tenerife, Spain

'Torrevieja Hospital, Alicante, Spain

${ }^{\text {h}}$ Allergy Clinic, Dr. Ramón Núñez Orjales, A Coruña, Spain

iHospital General Universitario Santa María del Rosell, Murcia, Spain

${ }^{j}$ Allergy Therapeutics Ibérica, Sant Joan Despí, Spain

Received 22 January 2021; Accepted 2 March 2021

Available online 1 July 2021

\section{KEYWORDS}

allergic rhinitis;

children and

adolescents;

microcrystalline

tyrosine;

mites;

real-world evidence; subcutaneous aller-

gen immunotherapy

\begin{abstract}
Evidence regarding allergen immunotherapy (AIT) in pediatric population is scarce. We have assessed safety and effectiveness of subcutaneous AIT with a microcrystalline tyrosine (MCT)associated mite allergoid, Acarovac Plus ${ }^{\circledR}$, in children and adolescents with allergic rhinitis (AR), with and without asthma, in the real-world setting. This was a retrospective, multicenter study including children and adolescents aged 5 years to 17 years with AR, with and without asthma, and sensitized to mites, receiving AIT with Acarovac Plus ${ }^{\circledR}$ during $\geq 6$ months. Primary and secondary objectives were safety and effectiveness, respectively. Effectiveness variables were assessed during 12 months before and after AIT and included unscheduled visits to the healthcare center and emergency room admissions, rhinitis and asthma symptoms according to ARIA and GEMA classifications, respectively, medication use, and patients' and physicians' disease perception graded on a visual analog scale (VAS). All 79 patients included had a mean (SD) age of 12.7 (3.3) years. Two patients experienced systemic adverse reactions
\end{abstract}

*Corresponding author: Anna Sala-Cunill, Allergy Section, Internal Medicine Department, Hospital Universitari Vall d’Hebrón, Passeig de la Vall d'Hebron, 119-129, 08035 Barcelona, Spain. Email address: annasala7@gmail.com 
(none severe). Unscheduled visits to the healthcare center and emergency room admissions decreased (mean (SD) 3.02 [2.48] and 0.63 [1.35] vs. 1.08 [1.38] and 0.09 [0.38], before and after treatment, $p<0.001$ and $p=0.001$, respectively). After AIT, rhinitis and asthma classification changed ( $p<0.0001$ for all classifications), showing improvements in symptoms and a significant decrease in rhinitis and use of medication for asthma and VAS scores grading patients' and physicians' disease perception $(p<0.001)$. In conclusion, these results show that AIT with an MCT-associated mite allergoid appears safe and effective in children and adolescents with AR treated in the real-world setting.

(C) 2021 Codon Publications. Published by Codon Publications.

\section{Introduction}

Allergic diseases cause severe burden to healthcare systems and impair patients' quality of life due to their high prevalence and associated chronicity. ${ }^{1}$ Starting during childhood as atopic dermatitis and/or allergic rhinitis (AR), allergic diseases impact children's daily functioning and school productivity and progress throughout adulthood, often with associated allergic conditions, such as asthma. ${ }^{2}$ Allergic diseases are caused by sensitization to different allergens and, in indoor environments, house dust mites (HDMs) are their major source, causing perennial allergic diseases upon prolonged exposure. ${ }^{3}$ Unlike other allergens, the degree of children's exposure to those from HDMs correlates with the risk of developing airway hyper-responsiveness. ${ }^{4,5}$ In this context, treatments aiming to modify the course of AR by targeting its underlying cause may curb its impact on children's daily lives and the risk of developing allergic asthma during adulthood. ${ }^{6}$

Even though the mainstay treatment for AR is pharmacotherapy, allergen immunotherapy (AIT) is the only treatment able to modify the course of the disease by inducing immune tolerance through the sublingual or subcutaneous administration of the allergen at controlled doses. ${ }^{6}$ Even though AIT is strongly recommended to treat adults with $A R$, recommendations to treat children and adolescents are moderate despite the reported safety in this population, particularly for subcutaneous immunotherapy (SCIT), due to the scarcity of efficacy studies. ${ }^{7-10}$ Furthermore, the effects of AIT in children and adolescents sensitized to HDMs are still controversial and more studies are needed to strengthen recommendations. ${ }^{6,11}$ Nevertheless, previous studies in patients with $A R$ have suggested that, besides controlling symptoms, AIT might provide additional long-term clinical benefits such as decreasing the risk of developing asthma and new sensitizations. ${ }^{12-14}$ Among the different HDM-specific AIT, Acarovac Plus ${ }^{\circledR}$ (Allergy Therapeutics, Worthing, UK), a purified allergen extract from mites modified with glutaraldehyde and associated with microcrystalline tyrosine (MCT) as an adjuvant, has shown clinical benefits in previous real-world studies including adults with AR. ${ }^{15}$

Despite the extended use of AIT in children and adolescents with AR to treat HDM allergy, the evidence obtained specifically in pediatric populations is scarce and mostly limited to clinical trials, likely limiting its direct application outside controlled settings. ${ }^{7,16-18}$ In this retrospective study, we have assessed the safety and efficacy of AIT with Acarovac Plus ${ }^{\circledast}$ in children and adolescents with AR, with and without asthma, and sensitized to different mite species in the real-world setting.

\section{Materials and Methods}

\section{Study Design and Population}

This was an observational, retrospective, multicenter study including patients aged 5 to 17 years with allergic rhinitis, with or without asthma, caused by mites (i.e., Dermatophagoides pteronyssinus, Dermatophagoides farinae, Lepidoglyphus destructor, and/or Blomia tropicalis), and was a sub-analysis of a previously published study including children, adolescents, and adults. ${ }^{19}$ Patients treated with the allergen-specific immunotherapy Acarovac Plus ${ }^{\circledR}$ in routine clinical practice in 18 Spanish hospitals for $\geq 6$ months were included in the study, whereas patients with poor treatment adherence were excluded. Data were obtained between August 2018 and January 2019 from clinical medical records, both data 12 months before AIT administration (pre-treatment period) and 12 months after AIT administration (post-treatment period) were recorded. Legal representatives of all patients $<18$ years signed a written informed consent before any information was recorded. The study was conducted in accordance with the Helsinki Declaration and the local Personal Data Protection Law (LOPD 15/1999); the study protocol was approved by the Ethics Committee of Hospital Vall d'Hebrón (Barcelona, Spain).

\section{Treatment and Administration Regimen}

Acarovac Plus ${ }^{\circledR}$ is composed of purified allergen extracts of mites (i.e., Dermatophagoides pteronyssinus, Dermatophagoides farinae, Lepidoglyphus destructor, and/ or Blomia tropicalis), modified with glutaraldehyde and associated with MCT, in an injectable suspension for subcutaneous administration. Acarovac Plus ${ }^{\circledR}$ is administered in two phases, an up-dosing phase, consisting in four increasingly higher doses of the allergen starting with $0.05 \mathrm{~mL}$ (i.e., $0.05,0.1,0.3$, and $0.5 \mathrm{~mL}$ ), and a maintenance phase, 
consisting in the administration of a $0.5-\mathrm{mL}$ dose every 6-8 weeks. During the up-dosing phase, Acarovac Plus ${ }^{\circledR}$ is administered at weekly or bi-weekly intervals following three different regimens according to the Summary of Product Characteristics (SmPC).

\section{Endpoints and Variables}

Variables collected from patients' medical records included demographic (age and sex), clinical (i.e., disease diagnosis, years of allergic disease evolution, sensitizing allergens, and other allergic diseases), and treatment data (i.e., AIT regimen, start date, and use of symptomatic medication to treat allergic rhinitis and asthma).

The primary objective of this study was to evaluate the safety and tolerability of Acarovac Plus ${ }^{\circledR}$ in routine clinical practice. Safety was assessed by measuring the number and severity of adverse reactions collected from medical records and coded by System Organ Class (SOC) and Preferred Term (PT) of the Medical Dictionary for Regulatory Activities (MedDRA). Adverse reactions were defined following the recommendations of the European Medicines Agency (EMA), and systemic adverse reactions were graded according to the World Allergy Organization (WAO). ${ }^{20,21}$

The secondary objective was to assess the effectiveness of the product in routine clinical practice. Effectiveness measures included the number of unscheduled visits to a physician/healthcare center due to allergy symptoms, number of visits to the emergency room, frequency and intensity of rhinitis (ARIA criteria), severity and control of asthma (GEMA criteria), use of medication to treat rhinitis and asthma, and VAS score from the patients' and physicians' perspective. Rhinitis was classified according to Allergic Rhinitis and its Impact on Asthma (ARIA) guidelines, and asthma was classified according to the "Guía Española para el Manejo del Asma" (GEMA), the Spanish version of the Global Initiative for Asthma (GINA) classification. ${ }^{22-25}$ ARIA classifies AR in two different dimensions-frequency and intensity-which include two and three categories, respectively. Ranging from less to more severe, AR frequency is classified in intermittent and persistent, whereas AR intensity is classified as mild, moderate, and severe. ${ }^{23,25}$ Likewise, GEMA and GINA classify asthma in two dimensions that, together, result in four categories, including, from less to more severe, intermittent, mild persistent, moderate persistent, and severe persistent. ${ }^{22,24}$ For allergic rhinitis and asthma, a change towards a less severe symptom category was considered a symptom and/or medication reduction. Additionally, asthma control was classified according to GEMA by assessing several items, including episodes, symptoms between crises, wheezing, nocturnal/ on-waking symptoms, need of rescue medication (SABA), and pulmonary function, including FEV1 (forced expiratory volume) and PEF (peak expiratory flow). ${ }^{22}$ During a routine visit to the specialist, patients and their legal representatives were informed about the study and signed a written informed consent. In addition, patients and parents of young patients graded allergic disease symptoms before and after administration of AIT using a Visual Analog Scale
(VAS) on a $10 \mathrm{~cm}$-long line. Likewise, physicians graded patients' allergic disease before and after treatment.

\section{Statistical Analysis}

This study focused on the analysis of the pediatric population ( $<18$ years, i.e., children and adolescents) of our previous study, which also included adults ( $>18$ years). ${ }^{19}$ Categorical variables were described as frequencies and percentages, and quantitative variables as the mean and standard deviation (SD) and/or the median and interquartile range (IQR) or range. Categorical variables, such as the distribution of patients in categories between visits, were compared using the McNemar test; the Bhapkar or Bowker's test of symmetry was performed for less than two categories. To compare quantitative data between different periods (paired data), the non-parametric Wilcoxon test was used. The significance threshold for all bivariate analyses was set as two-sided $\alpha=0.05$. All analyses were performed using the statistical package support SAS version 9.4.

\section{Results}

\section{Demographic, Clinical, and Treatment Characteristics of Study Patients}

Of the 306 patients included in this study, 79 (25.8\%) were children and adolescents (aged 5 to 17 years), with a mean (SD) age of 12.7 (3.3) years and they were recruited from 18 centers. Table 1 summarizes the demographic, clinical, and treatment characteristics of the pediatric population. Of the 21 pediatric patients with other allergic diseases, 11 (52.4\%) had atopic dermatitis, six (28.6\%) had conjunctivitis, six (28.6\%) had food allergy, and two (9.5\%) had drug allergy. Maintenance doses were administered at 4-week and 6-week intervals in 31 (39.2\%) and 48 (60.8\%) patients, respectively.

\section{Safety Outcomes}

Four (5.0\%) patients experienced a total of 20 local adverse reactions and two (2.5\%) experienced a total of nine systemic adverse reactions with mild and moderate symptoms. Each symptom and sign appearing after one administration was considered an adverse reaction and therefore, each administration could lead to multiple reactions, the characteristics of which are summarized in Table 2. Serious adverse reactions and use of epinephrine were not reported. Local adverse reactions were injection site erythema $(n=5)$, swelling $(n=5)$, pruritus $(n=3)$, pain $(n=3)$, edema $(n=2)$, and warmth $(n=2)$; systemic adverse reactions were cough $(n=2)$, dyspnea $(n=1)$, oral pruritus $(n=1)$, throat irritation $(n=1)$, bronchospasm $(n=1)$, wheezing $(n=1)$, sneezing $(n=1)$, and rhinorrhea $(n=1)$, coded by SOC and PT of the MedRA.

\section{Evolution of Visits to the Healthcare Center}

Mean (SD) number of unscheduled visits to the healthcare center due to allergy symptoms during the 12 months before 
Table 1 Demographic, clinical, and treatment characteristics of study patients, $n(\%) n=79$.

\begin{tabular}{|c|c|}
\hline \multicolumn{2}{|l|}{ Demographic Characteristics } \\
\hline \multicolumn{2}{|l|}{ Age, years } \\
\hline 5-11 (children) & $30(38.0)$ \\
\hline $12-17$ (adolescents) & $49(62.0)$ \\
\hline \multicolumn{2}{|l|}{ Sex } \\
\hline Male & $42(53.2)$ \\
\hline Female & $37(46.8)$ \\
\hline \multicolumn{2}{|l|}{ Clinical Characteristics } \\
\hline \multicolumn{2}{|l|}{ Diagnosis } \\
\hline Rhinitis & $36(45.6)$ \\
\hline Rhinitis + Asthma & $43(54.4)$ \\
\hline \multicolumn{2}{|l|}{ Other Allergic Diseases } \\
\hline Yes & $21(26.6)$ \\
\hline No & $58(73.4)$ \\
\hline \multicolumn{2}{|l|}{ Allergen Sensitization } \\
\hline Dermatophagoides pteronyssinus & 79 (100) \\
\hline Dermatophagoides farinae & $68(86.1)$ \\
\hline Lepidoglyphus destructor & $17(21.5)$ \\
\hline Blomia tropicalis & $5(6.3)$ \\
\hline Pollens & $20(25.3)$ \\
\hline \multicolumn{2}{|l|}{ Treatment Characteristics } \\
\hline \multicolumn{2}{|l|}{ Immunotherapy Composition } \\
\hline D. pteronyssinus $50 \% / D$. farinae $50 \%$ & $54(68.4)$ \\
\hline D. pteronyssinus $100 \%$ & $15(19.0)$ \\
\hline D. farinae $100 \%$ & $1(1.3)$ \\
\hline D. pteronyssinus $50 \% /$ L. destructor $50 \%$ & $7(8.9)$ \\
\hline Dermatophagoides 50\%/B. tropicalis 50\% & $2(2.5)$ \\
\hline \multicolumn{2}{|l|}{ Immunotherapy Regimen } \\
\hline Conventional & $20(25.3)$ \\
\hline Cluster & $33(41.8)$ \\
\hline Other (Off-Label) & $26(32.9)$ \\
\hline
\end{tabular}

and after AIT was $3.02(2.48)(n=45)$ and $1.08(1.38)(n=53)$ in all patients with available data, and $3.85(2.81)(n=26)$ and $1.30(1.58)(n=30)$ in patients with asthma (Figure 1A). Likewise, mean (SD) number of emergency room admissions due to allergy symptoms during the 12 months before and after AIT was $0.63(1.35)(n=60)$ and $0.09(0.38)(n=65)$ in all patients with available data, and $1.12(1.70)(n=32)$
(A)

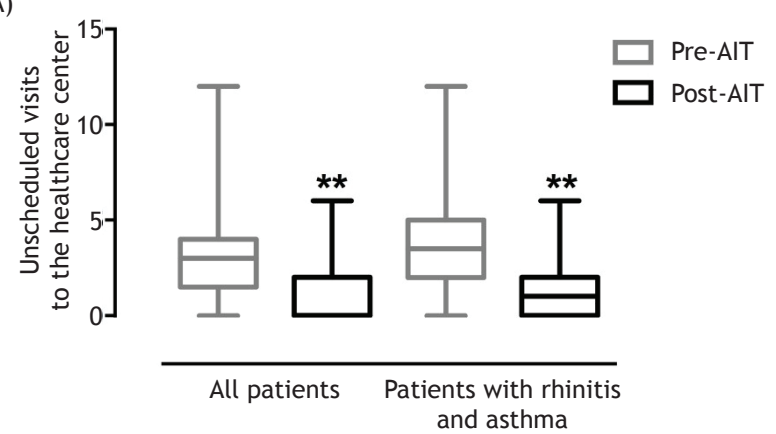

(B)

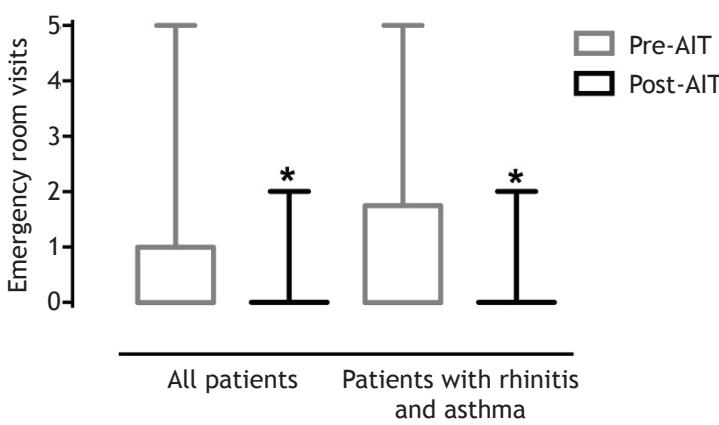

Figure 1 Box plot of unscheduled visits to the healthcare center (A) and emergency room admissions (B) before and after treatment for all study populations and patients with asthma. The box represents the interquartile range, the whiskers represent minimum and maximum values, and the horizontal line inside the box is the median. Wilcoxon test, ${ }^{*} p=0.001$ and ${ }^{* *} p<0.001$.

and $0.17(0.51)(n=35)$ in patients with asthma (Figure 1B). The frequency of patients experiencing unscheduled visits to the healthcare center significantly decreased from 37 (46.8\%) to 26 (32.9\%) (McNemar test, $p=0.003$ ) during the 12 months before and after AIT, respectively. Likewise, the frequency of patients visiting the emergency room significantly decreased from $16(20.3 \%)$ to four (5.1\%) (McNemar test, $p=0.002$ ) during the 12 months before and after AIT, respectively.

Table 2 Adverse reactions according to phase, treatment regimen, and age group, $n(\%) n=29$.

\begin{tabular}{|c|c|c|c|c|c|c|c|c|}
\hline & \multirow[b]{2}{*}{ Total } & \multicolumn{2}{|c|}{ Phase } & \multicolumn{3}{|c|}{ Regimen } & \multicolumn{2}{|c|}{ Age group } \\
\hline & & Up-Dosing & Maintenance & Conventional & Cluster & Other & Children & Adolescents \\
\hline All adverse reactions & $29^{a}$ & $15(51.7)$ & $14(48.3)$ & $4(13.8)$ & $18(62.1)$ & $7(24.1)$ & $9(31.0)$ & $20(69.0)$ \\
\hline \multicolumn{9}{|l|}{ Intensity } \\
\hline Mild & $17(58.6)$ & $11(73.3)^{\mathrm{b}}$ & $6(42.9)$ & $0(0)$ & $10(55.6)$ & 7 (100) & $0(0)$ & $17(85.0)$ \\
\hline Moderate & $12(41.4)$ & $4(26.7)$ & $8(57.1)$ & $4(100)$ & 8 (44.4) & $0(0)$ & $9(100)$ & $3(15.0)$ \\
\hline \multicolumn{9}{|l|}{ Type } \\
\hline Local & $20(69.0)$ & $15(100)$ & $5(35.7)$ & $4(100)$ & $13(72.2)$ & $3(42.9)$ & $4(44.4)$ & $16(80.0)$ \\
\hline Systemic & $9(31.0)$ & $0(0)$ & $9(64.3)$ & $0(0)$ & $5(27.8)$ & $4(57.1)$ & $5(55.6)$ & $4(20.0)$ \\
\hline
\end{tabular}

aEach symptom and sign appearing simultaneously after one administration was considered one adverse reaction.

bPercentages were calculated with respect to the total in each column category. 


\section{Evolution of Symptoms}

The frequency and intensity of rhinitis and asthma, classified according to ARIA and GEMA, respectively, changed during the 12 months after AIT compared with the previous 12 months. Regarding rhinitis, the frequency of symptoms decreased in $57(72.2 \%)$ patients and remained unchanged in seven (8.9\%) and $15(19.0 \%)$ patients with intermittent and persistent rhinitis, respectively (McNemar for $>2$ categories, $p<0.0001$ ) (Figure 2A). Similarly, symptom severity changed toward less severe categories in $62(78.5 \%)$ patients, and in two $(2.5 \%), 14$ $(17.7 \%)$, and one $(1.3 \%)$ patient with mild, moderate, and severe rhinitis, respectively, remained unchanged (McNemar for $>2$ categories, $p<0.0001$ ) (Figure 2B). Overall, rhinitis changed toward less severe categories in $76(96.2 \%)$ patients, of which $12(15.2 \%)$ reported no symptoms, remained unchanged in three $(3.8 \%$; one patient with severe intermittent and two with moderate persistent rhinitis), and did not get worsened in any patients 12 months after AIT administration. Regarding the effectiveness of AIT on asthma evolution, overall, asthma improved in $36(83.7 \%)$ patients; of which 15 (34.9\%) stopped reporting asthma symptoms after AIT administration, remained the same in seven $16.3 \%$; one with mild persistent and six with intermittent asthma), and did not get worsened in any patients (McNemar test for $>2$ categories, $p<0.0001$ ) (Figure $2 C$ ). The percentage of children and adolescents with partial and bad asthma control decreased from $55.8 \%$ and $4.7 \%$ to $7.0 \%$ and $0 \%$, respectively, whereas the percentage of patients with good and complete asthma control increased from $34.9 \%$ and $4.7 \%$ to $39.5 \%$ and $53.5 \%$ before and after AIT, respectively (McNemar test for $>2$ categories, $p<0.0001$ ).

\section{Evolution of Use of Medication for Rhinitis and Asthma}

The use of medication to treat rhinitis and asthma symptoms during the post-treatment period significantly changed compared with the pre-treatment period. Regarding medication to treat AR, the frequency of patients using oral antihistamines and nasal corticosteroids significantly decreased from $73 \%$ and $48 \%$ during the pre-treatment period to $64 \%$ and $26 \%$ during the post-treatment period, respectively (McNemar test $p<0.001$ for both medications) (Figure 3A). Analysis by sex and age group (children and adolescents) showed significant changes in all groups, with the exception of the use of nasal corticosteroids in children, which decreased, albeit not significantly (Figure 3B-E).

Similarly, the frequency of patients using short-acting beta- 2 agonists (SABAs) and inhaled corticosteroids (ICS) to treat asthma symptoms significantly decreased from $34 \%$ to $13 \%$ and from $30 \%$ to $17 \%$ during the pre-treatment and post-treatment periods, respectively (McNemar test $p<0.001$ for SABAs and $p=0.004$ for ICS). The modest decrease in the use of leukotriene receptor antagonists (LTRAs) and long-acting beta-2 agonists (LABAs) after AIT lacked statistical significance $(p=0.508$ and $p=0.289$, respectively) (Figure 4A). While changes in the use of SABA remained similar across sex and age groups, changes in the
(A)

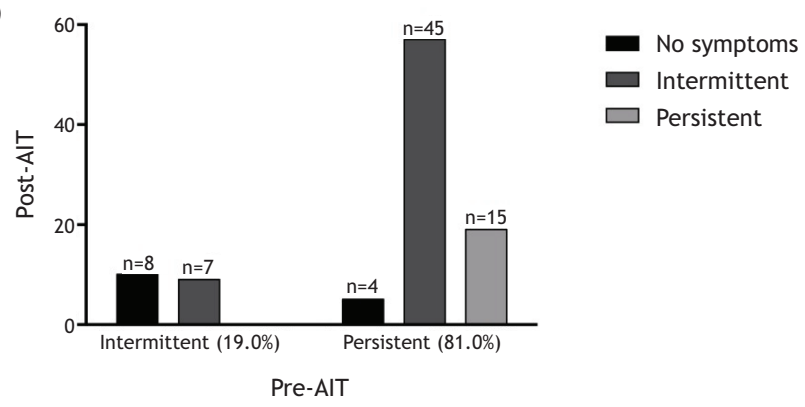

(B)

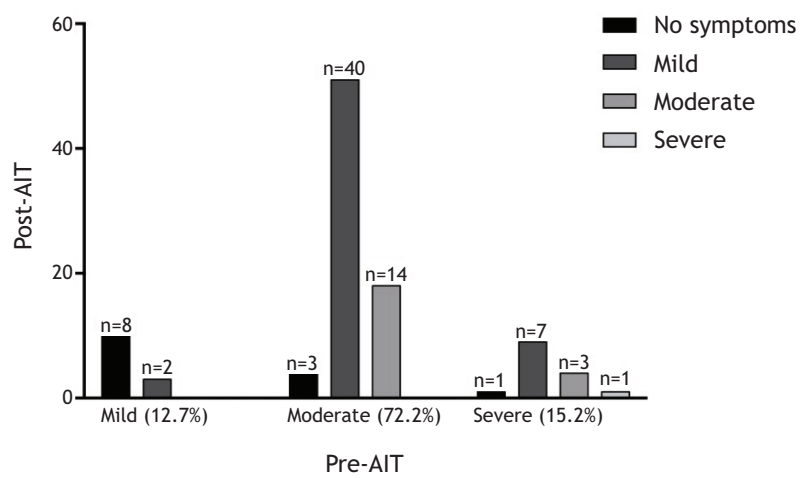

(C)

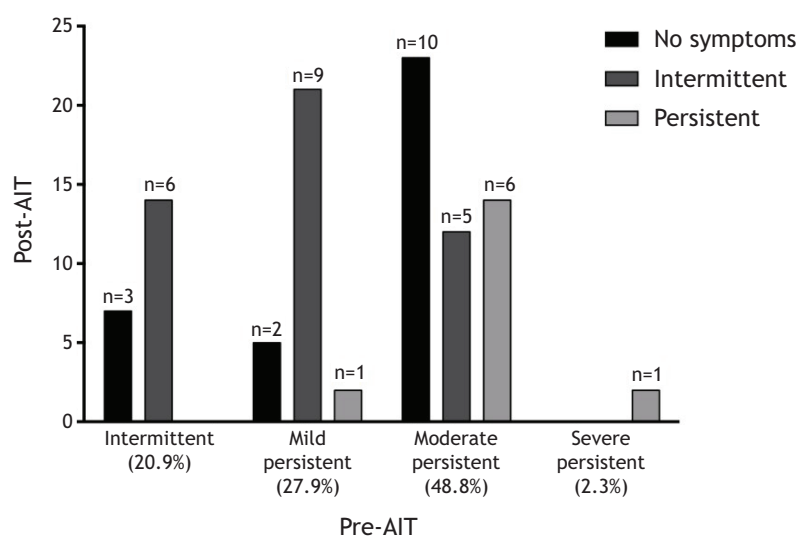

Figure 2 Evolution of rhinitis frequency $(A)$, rhinitis severity (B), and asthma severity (C) according to the ARIA and GEMA classifications, respectively. The percentage of patients in each category before and after treatment is shown on the X-axis category labels and represented by columns, respectively. AIT, allergen immunotherapy; ARIA, Allergic Rhinitis and its Impact on Asthma; GEMA, "Guía Española para el Manejo del Asma." McNemar test, $p<0.0001$, for $>2$ categories (Bowker's test of symmetry) for the distribution of paired-sample percentages for the three comparisons.

use of inhaled corticosteroids in female $(\mathrm{n}=22)$ and children $(n=21)$ lacked statistical significance (Figure 4B-E) and changes in use of LABAs and LTRAs after AIT remained not significant (Figure 4F-I).

\section{Patients' and Physicians' Disease Perception}

Consistent with the changes in effectiveness variables, patients' and physicians' perception of disease severity 
(A)

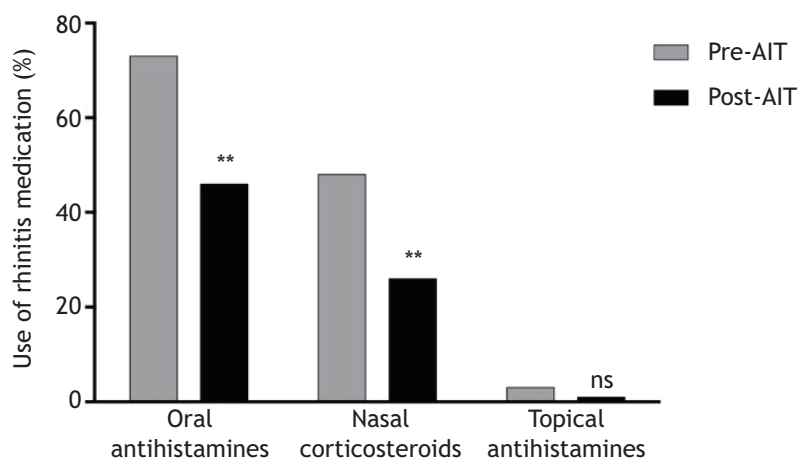

(B)

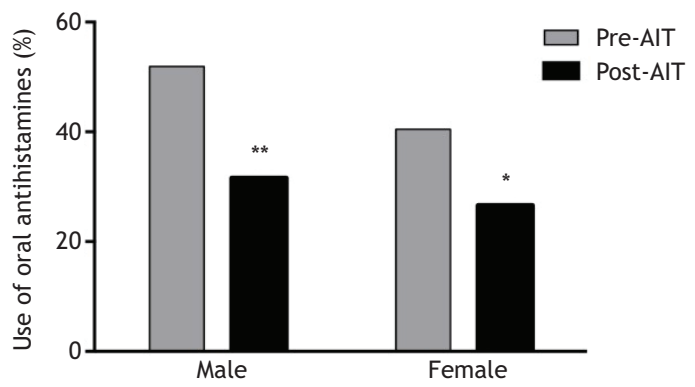

(D)

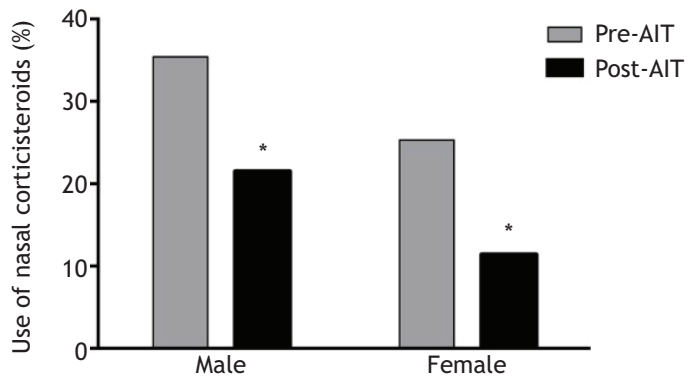

(C)

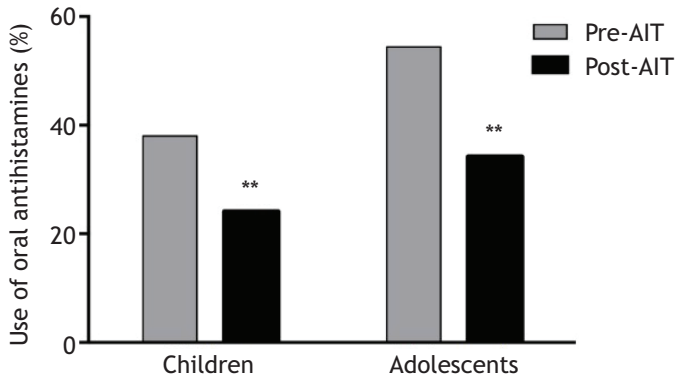

(E)

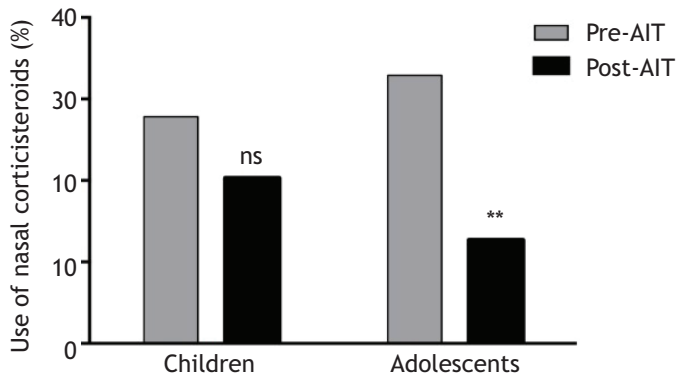

Figure 3 Evolution of the use of the indicated medication to treat rhinitis symptoms overall (A) and according to sex (B, D) and age $(C, E)$ before and after treatment in patients with rhinitis. Ns, not significant. McNemar test ${ }^{*} p<0.05,{ }^{* *} p<0.001$.

after AIT significantly changed compared with their perception before treatment. Mean (SD) patients' VAS scores decreased from 8.01 (1.24) to 3.22 (2.14) and physicians' VAS scores, from 7.92 (1.28) and 2.98 (1.93) before and after AIT, respectively. Figure 5 shows the median (IQR) VAS scores and the results of the statistical test used for comparison.

\section{Discussion}

In this retrospective study, we have provided real-world evidence that a microcrystalline tyrosine-associated mite allergoid (Acarovac Plus ${ }^{\circledR}$ ) appears to be safe and effective in children and adolescents with allergic rhinitis, with and without asthma, and sensitized to different mite species. Patients receiving this AIT product experienced a low incidence of local and systemic adverse reactions, and no severe adverse reactions were reported. Rhinitis and asthma improved after 12 months of treatment, which is shown by significant changes in their classification, with a concomitant reduction in unscheduled visits to the healthcare center and the emergency room and in the use of medication.

Like other medications, AIT products prescribed in children and adolescents (i.e., aged 5 to 17 years) should be individually evaluated for their indication in this age group. Hence, European regulations require companies to obtain safety and efficacy evidence of their AIT products from double-blind, placebo-controlled trials. ${ }^{26-28}$ However, fewer trials are conducted in this age group, likely due to their associated practical and ethical concerns. ${ }^{29}$ For this reason, in pediatric patients sensitized to mites, evidence from trials is scarce and guideline recommendations are based on a few studies including mixed age groups. ${ }^{7,9}$ Furthermore, the few trials conducted in children and adolescents with 
(A)

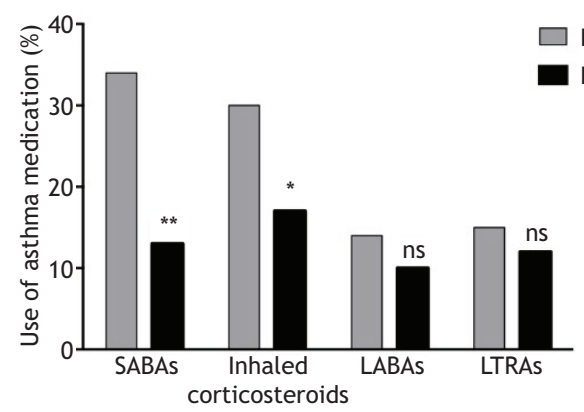

(B)

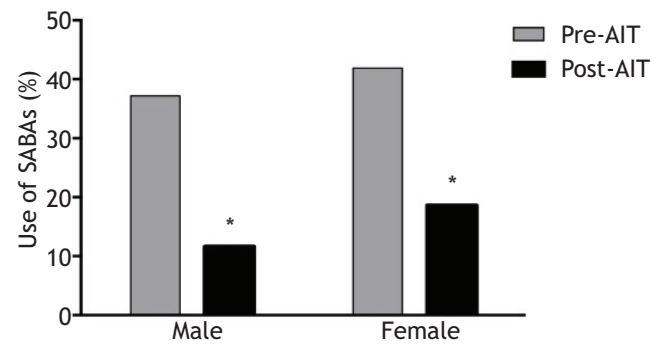

(D)

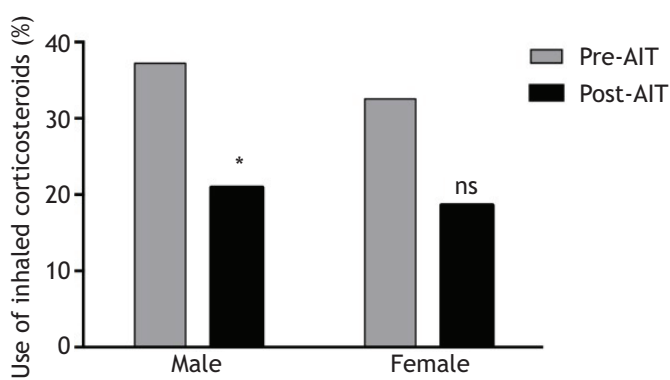

(F)

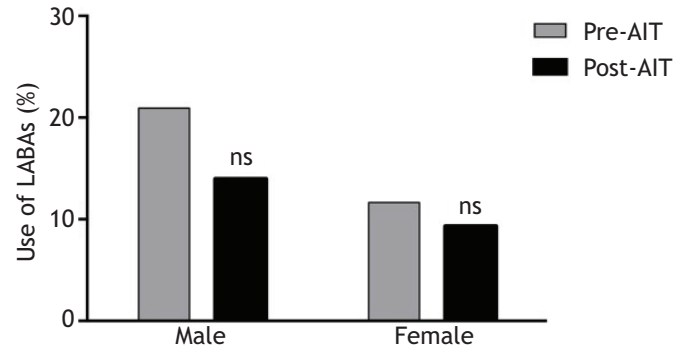

(H)

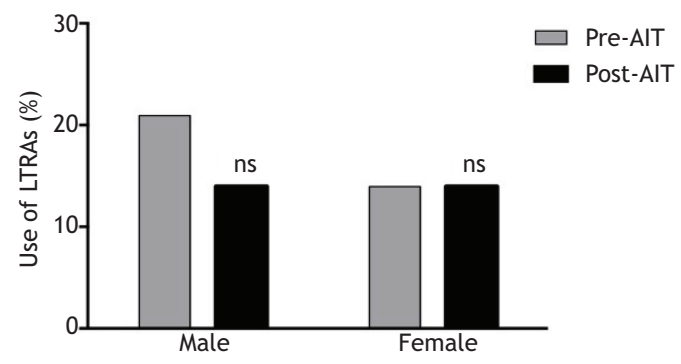

(C)

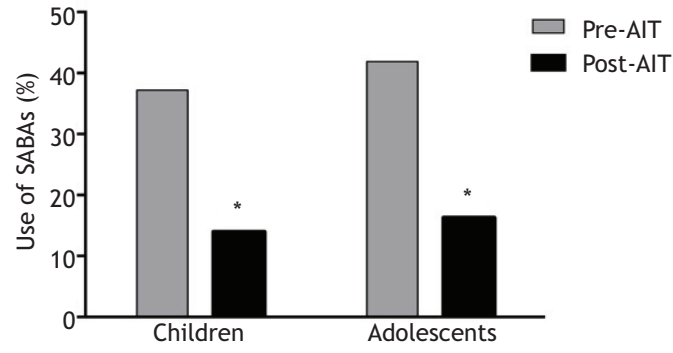

(E)

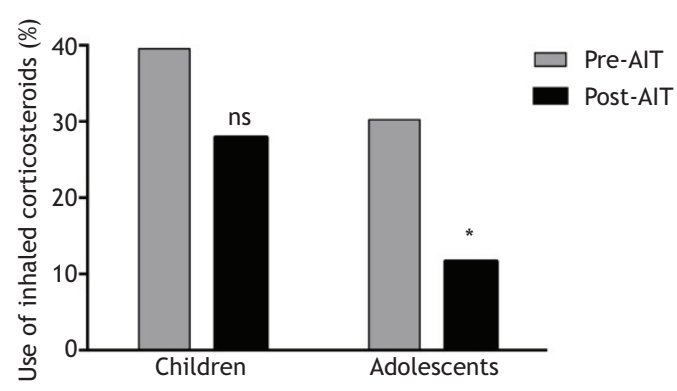

(G)

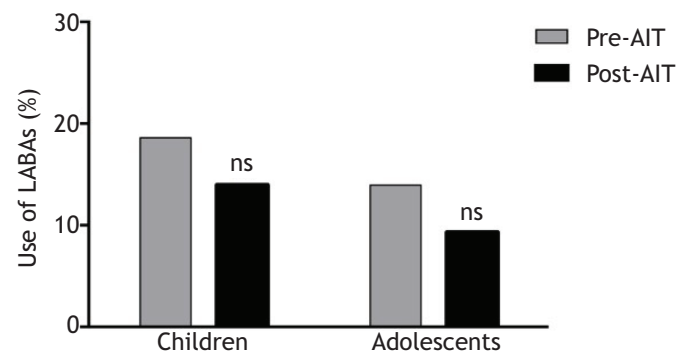

(I)

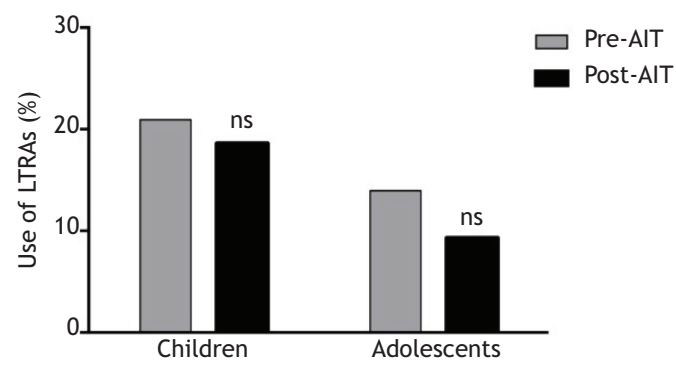

Figure 4 Evolution of the use of the indicated medication to treat asthma symptoms overall (A) and according to sex (B, D) and age $(C, E)$ before and after treatment in patients with rhinitis and asthma. McNemar test ${ }^{*} p<0.05,{ }^{* *} p<0.001$. 


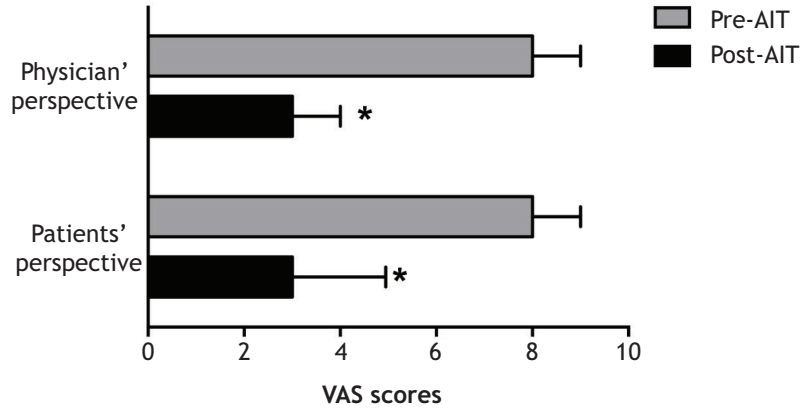

Figure 5 VAS scores grading patients' (A) and physicians' (B) perception of allergic disease before and after treatment. The columns and error bars represent the median and interquartile range, respectively. VAS, Visual Analog Scale. "Wilcoxon test, $p<0.0001$.

AR are typically focused on SLIT with Dermatophagoides extracts, excluding other common mite species, and, to our knowledge, not many have focused on SCIT. ${ }^{30-36}$ In a previous observational study, we retrospectively analyzed the safety and effectiveness of SCIT with MCT-adjuvanted mite allergoids in a population aged 5 to 65 years with AR, with and without asthma, treated according to the routine clinical practice. ${ }^{19}$ Considering the lack of evidence in the pediatric population, this retrospective sub-analysis of safety and effectiveness outcomes provides additional relevant evidence of AIT in this age group.

To evaluate the balance between the risk of systemic adverse reactions and efficacy, current guidelines demand more studies in children and adolescents. ${ }^{7,9}$ Regarding safety, a recent European survey including children aged 3 years to 18 years receiving SLIT and SCIT in the real-world setting, concluded that systemic reactions in this population were infrequent (29 systemic reactions, mostly associated with SCIT, in 24 [1.53\%] patients). This survey found that mite sensitization and formulations were associated with a lower risk of systemic reactions compared with pollen formulations, whereas native extracts were associated with a higher risk compared with allergoids. ${ }^{8}$ Similar to this survey, in this study, the frequency of adverse reactions was low, with four patients experiencing local reactions and two experiencing mild-to-moderate systemic reactions, none of them were serious, supporting the safety of Acarovac Plus ${ }^{\circledR}$ in children and adolescents treated in the real-world setting.

In addition to its safety, results obtained in this study showed a favorable disease evolution 12 months after starting AIT. Even though treatments and measures are heterogeneous between different studies, precluding direct comparisons, results from previous large prospective and retrospective controlled studies assessing the use of medication, VAS scores grading disease perception, and QoL scores showed a clinical benefit of SCIT in the pediatric population. ${ }^{33,34}$ Similarly, we have shown that AIT with Acarovac Plus ${ }^{\circledR}$ resulted in a decreased use of medication to treat rhinitis and asthma and patients' and physicians' perception of reduced disease severity. However, we additionally analyzed rhinitis and asthma according to the ARIA and GEMA classifications, respectively, and the impact of AIT treatment on unscheduled visits to the healthcare center and emergency room admissions due to allergy symptoms-a recorded objective parameter-all of which further showed significant changes pointing to a satisfactory disease evolution 12 months after starting AIT. Of the objective parameters assessed, emergency room admissions, which are frequently caused by asthma exacerbations, showed a marked reduction after AIT (from mean [SD] 1.12 [1.70] to 0.17 [0.51]) in patients with concomitant asthma. Regarding the changes in the use of medication to treat asthma, the effects of AIT were more pronounced in adolescents compared with children and, to a lesser extent, in male compared with female.

Results from this study show a low incidence of local and systemic adverse reactions, none of them were severe, and a satisfactory disease evolution, and are in line with a favorable safety and effectiveness profile of MCT as an adjuvant in mite allergoid preparations. Of the different adjuvants used in marketed AIT products, MCT has shown a higher capacity in enhancing the Th1-driven immune response than aluminum hydroxide, which is used in most AIT preparations in Europe. ${ }^{37}$ MCT is a biodegradable adjuvant that, similar to aluminum hydroxide, precipitates the allergoid, producing a depot effect that enables a slow release of the allergen and the administration of AIT maintenance doses at longer intervals compared with other AIT products (6 weeks vs. 4 weeks). However, unlike aluminum, MCT is well tolerated and lacks the potential long-term and neurological toxicity associated with aluminum, which is particularly concerning in pediatric population. ${ }^{37,38}$ Furthermore, in mice, MCT induced IL-4 and IgE production in lower levels compared with aluminum, showing a more favorable immune response. ${ }^{39}$

Given the intrinsic limitations associated with its retrospective design and real-world setting, results from this study should be interpreted with caution. In addition to general limitations (i.e., missing data across variables and time points), the study design precluded the inclusion of variables not recorded in the routine clinical practice in Spain, such as Combined Symptom and Medication Scores (CSMS), total and specific IgE levels, and direct symptom measures. The European Academy of Allergy and Clinical Immunology $(\mathrm{EAACl})$ recommends including CSMS as the primary endpoint in studies assessing AIT to homogenize their methodologies. ${ }^{40}$ However, this study assessed other patient-reported variables, also serving as surrogate measures of treatment efficacy, including use of medication and symptom frequency and intensity. Similar to CSMS, these variables are potentially influenced by patients' subjectivity and therefore by a placebo effect, even though the extent of its contribution is unclear due to the lack of a placebo arm. However, this study additionally assessed objective variables as effectiveness outcomes, including changes in the number of unscheduled visits to the healthcare center and emergency room admissions, which are less likely to be influenced by a placebo effect. Moreover, results regarding patients' and physicians' perception may have been further influenced by a recall bias and should be interpreted with caution. Nevertheless, the results of this study assessing subjective and objective measures are consistent with a clinical benefit of AIT in children and 
adolescents after 1 year of treatment. Even though AIT is recommended during a 3-year course, this study intended to assess the safety and short-term effects of AIT, raising the need for future studies assessing a sustained (3-5 years of treatment) and long-term efficacy (years after end of treatment). Despite these limitations, this study assessed the safety and effectiveness of Acarovac Plus ${ }^{\circledR}$ in a population of children and adolescents treated in the routine clinical practice, confirming the favorable safety and effectiveness profile of SCIT outside clinical trials and providing useful information for clinicians.

\section{Conclusion}

The results of this study show that treatment with an MCTassociated mite allergoid appears to be safe and effective in children and adolescents with $A R$, with and without asthma, treated in the real-world setting. These findings warrant double-blind, placebo-controlled trials assessing AIT with mite extracts to treat rhinitis and asthma in pediatric populations to provide robust evidence toward the modification of current guidelines.

\section{Acknowledgments}

This study was supported by Allergy Therapeutics Ibérica. The authors would like to thank i2e3 Biomedical Research Institute for providing medical writing support during the preparation of the manuscript.

\section{Conflict of Interest}

AS-C has received consultancy fees from Allergy Therapeutics Ibérica, Merck, Circassia, ALK-Abelló, and Leti Pharma. IG-N has received personal fees from ALKAbelló, Stallergenes, and Mundipharma. AB, CT-B, and JLJ are employees of Allergy Therapeutics. ZMA-S, SL, JAM-T, MDM, and RN have nothing to disclose.

\section{References}

1. Bousquet J, Khaltaev N, Cruz AA, Denburg J, Fokkens WJ, Togias A, et al. Allergic Rhinitis and its Impact on Asthma (ARIA) 2008*. Allergy [Internet]. 2008 Apr 15 [cited 2020 Mar 6];63(11):8-160. Available from: https://onlinelibrary.wiley. com/doi/abs/10.1111/all.13805

2. Meltzer EO. Allergic Rhinitis. Immunol Allergy Clin North Am [Internet]. 2016 May 1 [cited 2020 Mar 29];36(2):235-48. Available from: https://linkinghub.elsevier.com/retrieve/pii/ S0889856115001137. https://doi.org/10.1016/j.iac.2015.12.002

3. Calderón MA, Linneberg A, Kleine-Tebbe J, De Blay F, Hernandez Fernandez de Rojas D, Virchow JC, et al. Respiratory allergy caused by house dust mites: What do we really know? J Allergy Clin Immunol [Internet]. 2015 Jul [cited 2020 Mar 29];136(1):38-48. Available from: https://linkinghub. elsevier.com/retrieve/pii/S0091674914014821. https://doi. org/10.1016/j.jaci.2014.10.012
4. Lodge CJ, Lowe AJ, Gurrin LC, Hill DJ, Hosking CS, Khalafzai RU, et al. House dust mite sensitization in toddlers predicts current wheeze at age 12 years. J Allergy Clin Immunol [Internet]. 2011 Oct [cited 2020 Sep 9];128(4):782-788.e9. Available from: https://linkinghub.elsevier.com/retrieve/pii/ S0091674911010608. https://doi.org/10.1016/j.jaci.2011.06.038

5. Illi S, von Mutius E, Lau S, Niggemann B, Grüber C, Wahn U. Perennial allergen sensitisation early in life and chronic asthma in children: A birth cohort study. Lancet [Internet]. 2006 Aug 26 [cited 2020 Mar 29];368(9537):763-70. Available from: https://linkinghub.elsevier.com/retrieve/pii/ S0140673606692866. https://doi.org/10.1016/S0140-6736 (06)69286-6

6. Halken S, Larenas-Linnemann D, Roberts $G$, Calderón MA, Angier $\mathrm{E}$, Pfaar $\mathrm{O}$, et al. EAACl guidelines on allergen immunotherapy: Prevention of allergy. Pediatr Allergy Immunol [Internet]. 2017 Dec [cited 2020 Mar 30];28(8):728-45. Available from: http://doi.wiley.com/10.1111/pai.12807.

7. Roberts G, Pfaar O, Akdis CA, Ansotegui IJ, Durham SR, Gerth van Wijk $R$, et al. EAACl Guidelines on Allergen Immunotherapy: Allergic rhinoconjunctivitis. Allergy [Internet]. 2018 Apr 1 [cited 2020 Apr 17];73(4):765-98. Available from: http://doi.wiley.com/10.1111/all.13317.

8. Rodríguez del Río P, Vidal C, Just J, Tabar Al, SanchezMachin I, Eberle P, et al. The European Survey on Adverse Systemic Reactions in Allergen Immunotherapy (EASSI): A paediatric assessment. Pediatr Allergy Immunol [Internet]. 2017 Feb [cited 2020 Mar 31];28(1):60-70.https://doi.org/10.1111/ pai.12660

9. Dhami S, Nurmatov U, Arasi S, Khan T, Asaria M, Zaman H, et al. Allergen immunotherapy for allergic rhinoconjunctivitis: A systematic review and meta-analysis. Allergy [Internet]. 2017 Nov [cited 2020 Sep 4];72(11):1597-631. http://doi.wiley. com/10.1111/all.13201.

10. Agache I, Lau S, Akdis CA, Smolinska S, Bonini M, Cavkaytar O, et al. EAACl Guidelines on Allergen Immunotherapy: House dust mite-driven allergic asthma. Allergy [Internet]. 2019 May 16 [cited 2020 Sep 3];74(5):855-73. https://doi.org/10.1111/ all.13749

11. Rudman Spergel AK, Minnicozzi M, Wheatley LM, Togias A. Is Allergen Immunotherapy in Children Disease Modifying? A Review of the Evidence. Curr Allergy Asthma Rep [Internet]. 2018 Sep 11 [cited 2020 Sep 3];18(9):47. https://doi. org/10.1007/s11882-018-0801-y

12. Jacobsen L, Niggemann B, Dreborg S, Ferdousi HA, Halken S, Høst A, et al. Specific immunotherapy has longterm preventive effect of seasonal and perennial asthma: 10-year follow-up on the PAT study. Allergy [Internet]. 2007 Aug [cited 2020 Sep 2];62(8):943-8. https://doi. org/10.1111/j.1398-9995.2007.01451.x

13. Schmitt J, Schwarz K, Stadler E, Wüstenberg EG. Allergy immunotherapy for allergic rhinitis effectively prevents asthma: Results from a large retrospective cohort study. J Allergy Clin Immunol [Internet]. 2015 Dec [cited 2020 Sep 2];136(6):1511-6. https://doi.org/10.1016/j.jaci.2015.07.038

14. Eng PA, Borer-Reinhold M, Heijnen IAFM, Gnehm HPE. Twelve-year follow-up after discontinuation of preseasonal grass pollen immunotherapy in childhood. Allergy [Internet]. 2006 Feb [cited 2020 Sep 2];61(2):198-201. https://doi. org/10.1111/j.1398-9995.2006.01011.x

15. Roger A, Malet A, Moreno V, Parra A, Gutiérrez D, Lleonart R, et al. Real-life effect of a microcrystalline tyrosine adjuvanted mite immunotherapy in patients with allergic rhinitis. Immunotherapy [Internet]. 2020 Jan [cited 2020 Mar 06];12(1):53-62. https://doi.org/10.2217/imt-2019-0205 
16. Calderón MA, Bousquet J, Canonica GW, Cardell L-O, Fernandez de Rojas DH, Kleine-Tebbe J, et al. Guideline recommendations on the use of allergen immunotherapy in house dust mite allergy: Time for a change? J Allergy Clin Immunol [Internet]. 2017 Jul [cited 2020 Mar 29];140(1):41-52. https:// doi.org/10.1016/j.jaci.2017.01.049

17. Devillier $P$, Demoly $P$, Molimard $M$. Allergen immunotherapy: What is the added value of real-world evidence from retrospective claims database studies? Expert Rev Respir Med [Internet]. 2020 Mar 4 [cited 2020 Mar 30];14(5):445-52. https://doi.org/10.1080/17476348.2020.1733417

18. Incorvaia C, Barberi S, Pastorello E, Ciprandi G. Allergic reactions after vaccination: Translating guidelines into clinical practice. Eur Ann Allergy Clin Immunol [Internet]. 2019 Jan [cited 2020 Sep 4];51(03):115. https://doi.org/10.23822/ EurAnnACl.1764-1489.84

19. Sala-Cunill A, Pérez-Formoso JL, Torán-Barona C, Almeida-Sánchez ZM, Álvarez-Fernández JA, García-Núñez I, et al. Safety and effectiveness of a microcrystalline tyrosine-associated mite extract immunotherapy for allergic rhinitis. Immunotherapy [Internet]. 2020 Sep 19 [cited 2020 Sep 7];12(13):1007-19. https://doi.org/10.2217/imt-2020-0194

20. Cox L, Larenas-Linnemann D, Lockey RF, Passalacqua G. Speaking the same language: The World Allergy Organization Subcutaneous Immunotherapy Systemic Reaction Grading System. J Allergy Clin Immunol [Internet]. 2010 Mar [cited 2020 Apr 14];125(3):569-574.e7. https://doi.org/10.1016/j. jaci.2009.10.060

21. EMA (European Medicine Agency). ICH E6 (R2) Good clinical Practice [Internet] [cited $2020 \mathrm{Apr}$ 4]. Available from: https:// www.ema.europa.eu/en/ich-e6-r2-good-clinical-practice

22. GEMA 4.2 Guía española para el manejo del asma (Spanish guidelines for asthma management) [Internet]. 2016 [cited 2020 Jan 11]. Available from: https://www.semg.es/index. $\mathrm{php} /$ consensos-guias-y-protocolos/102-gema-4-2

23. Brożek JL, Bousquet J, Agache I, Agarwal A, Bachert C, Bosnic-Anticevich S, et al. Allergic Rhinitis and its Impact on Asthma (ARIA) guidelines-2016 revision. J Allergy Clin Immunol [Internet]. 2017 Oct [cited 2020 Mar 10];140(4):9508. Available from: https://linkinghub.elsevier.com/retrieve/ $\mathrm{pii} / \mathrm{S} 0091674917309193$

24. Global Initiative for Asthma (GINA). Global Strategy for Asthma Management and Prevention [Internet]. 2019 [cited 2020 Sep 18]. Available from: https://ginasthma.org/wp-content/ uploads/2019/06/GINA-2019-main-report-June-2019-wms.pdf

25. Bousquet J, Khaltaev N, Cruz AA, Denburg J, Fokkens WJ, Togias A, et al. Allergic Rhinitis and its Impact on Asthma (ARIA) 2008*. Allergy [Internet]. $2008 \mathrm{Apr}$ [cited 2020 Mar 29];63:8-160. Available from: http://doi.wiley. com/10.1111/j.1398-9995.2007.01620.x

26. Calderon MA, Gerth van Wijk R, Eichler I, Matricardi PM, Varga EM, Kopp $M V$, et al. Perspectives on allergenspecific immunotherapy in childhood: An EAACl position statement. Pediatr Allergy Immunol [Internet]. 2012 Jun [cited 2020 Sep 4];23(4):300-6. https://doi. org/10.1111/j.1399-3038.2012.01313.x

27. Pfaar O, Gerth van Wijk R, Klimek L, Bousquet J, Creticos PS. Clinical trials in allergen immunotherapy in the age group of children and adolescents: Current concepts and future needs. Clin Transl Allergy [Internet]. 2020 Dec 24 [cited 2020 Jul 17];10(1):11. https://doi.org/10.1186/s13601-020-00314-1

28. EMA (European Medicine Agency). Human Medicines Development and Evaluation EMA/PDCO Standard Paediatric Investigation Plan for Allergen Products for Specific
Immunotherapy Revision 4. [Internet]. 2015 [cited 2020 Sep 8]. Available from: www.ema.europa.eu

29. Weimer K, Gulewitsch MD, Schlarb AA, Schwille-Kiuntke J, Klosterhalfen S, Enck P. Placebo effects in children: A review. Pediatr Res [Internet]. 2013 Jul 18 [cited 2020 Sep 10];74(1):96-102. Available from: http://www. nature.com/articles/pr201366. https://doi.org/10.1038/pr.2013.66

30. Nolte H, Bernstein DI, Nelson HS, Kleine-Tebbe J, Sussman GL, Seitzberg D, et al. Efficacy of house dust mite sublingual immunotherapy tablet in North American adolescents and adults in a randomized, placebo-controlled trial. J Allergy Clin Immunol [Internet]. 2016 Dec [cited 2020 Sep 8];138(6):16318. Available from: https://linkinghub.elsevier.com/ retrieve/pii/S0091674916307837. https://doi.org/10.1016/j. jaci.2016.06.044

31. Okubo K, Masuyama K, Imai T, Okamiya K, Stage BS, Seitzberg D, et al. Efficacy and safety of the SQ house dust mite sublingual immunotherapy tablet in Japanese adults and adolescents with house dust mite-induced allergic rhinitis. J Allergy Clin Immunol [Internet]. 2017 Jun [cited 2020 Sep 8];139(6):1840-1848.e10. Available from: https://linkinghub. elsevier.com/retrieve/pii/S0091674916312945. https://doi. org/10.1016/j.jaci.2016.09.043

32. Masuyama K, Okamoto Y, Okamiya K, Azuma R, Fujinami T, Riis $B$, et al. Efficacy and safety of SQ house dust mite sublingual immunotherapy-tablet in Japanese children. Allergy [Internet]. 2018 Dec [cited 2020 Sep 7];73(12):2352-63. https://doi.org/10.1111/all.13544

33. Song $\mathrm{Y}$, Long J, Wang $\mathrm{T}$, Xie J, Wang $M$, Tan G. Long-term efficacy of standardised specific subcutaneous immunotherapy in children with persistent allergic rhinitis due to multiple allergens including house dust mites. J Laryngol Otol [Internet]. 2018 Mar 28 [cited 2020 Sep 7];132(3):230-5. Available from: https://www.cambridge.org/core/product/ identifier/S0022215117002547/type/journal_article. https:// doi.org/10.1017/S0022215117002547

34. Jutel $M$, Brüggenjürgen $B$, Richter $H$, Vogelberg $C$. Realworld evidence of subcutaneous allergoid immunotherapy in house dust mite-induced allergic rhinitis and asthma. Allergy [Internet]. 2020 Aug 12 [cited 2020 Apr 1];75(8):2046-54. https://doi.org/10.1111/all.14240

35. Yukselen A, Kendirli SG, Yilmaz M, Altintas DU, Karakoc GB. Effect of one-year subcutaneous and sublingual immunotherapy on clinical and laboratory parameters in children with rhinitis and asthma: A randomized, placebo-controlled, double-blind, double-dummy study. Int Arch Allergy Immunol [Internet]. 2012 [cited 2021 Jan 2];157(3):288-98. Available from: https://www.karger.com/Article/FullText/327566. https://doi.org/10.1159/000327566

36. Calderon MA, Casale TB, Nelson HS, Demoly P. An evidence-based analysis of house dust mite allergen immunotherapy: A call for more rigorous clinical studies. J Allergy Clin Immunol [Internet]. 2013 Dec [cited 2021 Jan 2];132(6):132236. Available from: https://linkinghub.elsevier.com/ retrieve/pii/S009167491301381X. https://doi.org/10.1016/j. jaci.2013.09.004

37. Jensen-Jarolim E, Bachmann MF, Bonini S, Jacobsen L, Jutel $M$, Klimek L, et al. State-of-the-art in marketed adjuvants and formulations in Allergen Immunotherapy: A position paper of the European Academy of Allergy and Clinical Immunology (EAACI). Allergy [Internet]. 2020 Apr 21 [cited 2020 Mar 19];75(4):746-60. Available from: https://onlinelibrary.wiley.com/doi/abs/10.1111/all.14134. https://doi. org/10.1111/all.14134 
38. Alvaro-Lozano M, Akdis CA, Akdis M, Alviani C, Angier E, Arasi $\mathrm{S}$, et al. Allergen immunotherapy in children user's guide. Pediatr Allergy Immunol [Internet]. 2020 May 21 [cited 2020 Jul 21];31(S25):1-101. Available from: https://pubmed. ncbi.nlm.nih.gov/32436290/. https://doi.org/10.1111/pai.13189

39. Leuthard DS, Duda A, Freiberger SN, Weiss S, Dommann I, Fenini G, et al. Microcrystalline tyrosine and aluminum as adjuvants in allergen-specific immunotherapy protect from IgE-mediated reactivity in mouse models and act independently of inflammasome and TLR signaling. J Immunol
[Internet]. 2018 May 1 [cited 2020 Oct 28];200(9):3151-9. Available from: http://www.jimmunol.org/lookup/doi/ 10.4049/jimmunol.1800035. https://doi.org/10.4049/ jimmunol.1800035

40. Pfaar O, Demoly P, Gerth van Wijk R, Bonini S, Bousquet J, Canonica GW, et al. Recommendations for the standardization of clinical outcomes used in allergen immunotherapy trials for allergic rhinoconjunctivitis: An EAACI Position Paper. Allergy [Internet]. 2014 Jul [cited 2020 Apr 2];69(7):854-67. https:// doi.org/10.1111/all.12383 